Afriliyanti Muslimah ${ }^{1}$ Melvi Lesmana Alim² Citra $\mathrm{Ayu}^{3}$

\title{
Meningkatkan Kemampuan Berbahasa Anak Usia 5-6 Tahun Dengan Penerapan Metode Tanya Jawab
}

\begin{abstract}
Penelitian bertujuan untuk mengetahui peningkatan kemampuan berbahasa anak dengan penerapan metode tanya jawab pada anak. Jenis penelitian yang digunakan adalah Penelitian Tindakan Kelas yang dilakukan secara kolaboratif antara peneliti dengan guru kelas. Subjek penelitian ini adalah 15 anak kelompok B RA Aisyiyah Bustanul Athfal yang terdiri dari 10 anak perempuan dan 5 anak laki-laki. Objek penelitian adalah kemampuan berbahasa anak. Teknik pengumpulan data melalui observasi dan dokumentasi. Intrumen yang digunakan adalah lembar observasi ( chek list) dan dokumen foto anak. Teknik analisis data secara deskriptif kuantitatif. Hasil penelitian menunjukan bahwa terdapat peningkatan kemampuan berbahasa anak dengan penerapan metode tanya jawab. Hasil observasi pada pratindakan menunjukan bahwa kemampuan berbahasa anak belumberkembang dan rata-rata nya mendapat skor $22,2 \%$. Pada siklus I meningkat menjadi 43,48\% dan pada siklus II meningkat lagi menjadi 78\%. Dengan demikian, dapat disimpulkan bahwa dengan penerapan metode tanya jawab dapat meningkatkan kemampuan berbahasa anak.
\end{abstract}

Kata kunci: Kemampuan, Berbahasa, Metode Tanya Jawab

\begin{abstract}
The study aims to determine the improvement of children's language skills by applying the question and answer method to children. The type of research used is Classroom Action Research conducted collaboratively between researchers and classroom teachers. The subjects of this study were 15 children in group B RA Aisyiyah Bustanul Athfal consisting of 10 girls and 5 boys. The object of research is children's language skills. The technique of collecting data through observation and documentation. The instruments used are observation sheets (check list) and children's photo documents. Descriptive quantitative data analysis techniques. The results showed that there was an increase in children's language skills by applying the question and answer method. The results of observations on pre-action show that the language ability of children has not developed and the average score is $22.2 \%$. In the first cycle increased to $43.48 \%$ and in the second cycle increased again to $78 \%$. Thus, it can be concluded that the application of the question and answer method can improve children's language skills.
\end{abstract}

Keywords: Ability, Language, Question and Answer Methods

\footnotetext{
${ }^{1}$ Prodi PG-PAUD, FIP, Universitas Pahlawan Tuanku Tambusai, Riau, Indonesia. Email: afriliyantimuslimah@gmail.com

${ }^{2}$ Prodi PG-PAUD, FIP, Universitas Pahlawan Tuanku Tambusai, Riau, Indonesia

${ }^{3}$ Prodi PG-Pendidikan Bahasa Inggris, FIP, Universitas Pahlawan Tuanku Tambusai, Riau, Indonesia
}

Aulad : Journal on Early Childhood, 2018 1(1), 1 - 7 


\section{PENDAHULUAN}

Bahasa merupakan alat komunikasi yang sangat penting dalam kehidupanmanusia, karena disamping berfungsi sebagai alat untuk menyatakan pikiran dan perasaan kepada orang lain dan juga berfungsi sebagai alat untuk memahami perasaan dan pikiran orang lain. Kemampuan berbahasa tidak hanya diperlukan oleh manusia yang sudah dewasa saja, tetapi juga diperlukan bagi kehidupan anak. Dalam perkembangannya anak usia 3-6 tahun sedang mengalami fase peralihan dari masa egosentris ke masa sosial. Ia mulai sadar bahwa lingkungan tidak selalu sesuai dengan keinginannya sehingga ia harus belajar menyesuaikan diri kepada tuntutan lingkungannya itu. Menurut peraturan daerah Nomor 27 tahun 1990 tentang pendidikan prasekolah Bab I Pasal 1 ayat (2) Pendidikan di Taman Kanak-Kanak dilaksanakan dengan prinsip bermain sambil belajar atau belajar seraya bermain sesuai dengan perkembangan anak didik. Adapun tujuan TK berdasarkan Keputusan Menteri Pendidikan dan Kebudayaan Nomor 0486/U/92 tentang Taman Kanak-Kanak, adalah membantu meletakkan dasar ke arah perkembangan sikap pengetahuan, keterampilan, dan daya cipta yang diperlukan oleh anak, pertumbuhan serta perkembangan selanjutnya. Kemampuan yang dimiliki oleh manusia merupakan bekal yang sangat pokok. Dalam UU tentang Sistem Pendidikan nasional dinyatakan bahwa pendidikan Anak Usia dini (PAUD) adalah suatu upaya pembinaan yang ditujukan kepada anak sejak lahir sampai dengan usia enam tahun.

Pandangan ini diwakili oleh B.F Skinner, yang menekankan bahwa proses pemerolahan bahasa pertama dikendalikan dari luar diri si anak, yaitu oleh rangsangan yang diberikan melalui lingkungan. Istilah bahasa bagi kaum behavioris dianggap kurang tepat karena istilah 1bahasa itu menyiratkan suatu wujud, sesuatu yang dimiliki atau digunakan, dan sesuatu yang di lakukan. Padahal bahasa itu merupakan salah satu perilaku-perilaku manusia lainnya. Oleh karena itu, mereka lebih suka menggunakan istilah perilaku verbal (verbal behavior), agar tampak lebih mirip dengan perilaku kain yang harus dipelajari.

Berdasarkan pengamatan sementara yang peneliti lakukan di RA Aisyiyah Bustanul Athfal Sumber Makmur Kecamatan Tapung Kabupaten Kampar pada kelompok B 5-6 Tahun dengan jumlah 15 anak terdiri dari 10 anak perempuan dan 5 anak laki-laki. Keadaan awal pada kelas tersebut banyak sekali permasalahan dalam perkembangan berbahasa antara lain anak yang (BB: 7 orang), (MB: 6 orang), (BSH: 2 orang), (BSH: 0 orang). Berdasarkan data tersebut terdapat 9 anak yang mengalami kesulitan dalam berbahasa seperti ada 5 orang anak yang susah untuk di ajak berkomunikasi atau bisa di katakan lambat untuk menjawab pertanyaan yang diberi oleh gurunya (lambat merespon pertanyaan), ada juga 3 anak yang kemampuan berbahasanya kurang jelas cara pengucapannya (cedal), dan ada 1 anak yang pendiam serta jarang berbicara dengan guru ataupun teman-temannya.

Dari sekian banyak permasalahan yang terjadi pada anak maka penulis berupaya untuk meningkatkan kemampuan berbahasa anak pada kelompok B di RA. Aisyiyah Bustanul Athfal menggunakan metode tanya jawab. Metode tanya jawab adalah cara penyajian pelajaran dalam bentuk pertanyaan yang harus dijawab, terutama dari guru kepada anak, tetapi dapat pula dari anak kepada guru. Hal ini sejalan dengan pendapat Sudirman (1987: 120) yang mengartikan bahwa "metode tanya jawab adalah cara penyajian pelajaran dalam bentuk pertanyaan yang harus dijawab, terutama dari guru kepada anak, tetapi dapat pula dari anak kepada guru."

Aulad : Journal on Early Childhood, 2018 1(1), 1 - 7 
Sudirman (1987: 119) menyatakan bahwa metode tanya jawab ini dapat dijadikan sebagai pendorong dan pembuka jalan bagi anak untuk mengadakan penelusuran lebih lanjut (dalam rangka belajar) kepada berbagai sumber belajar seperti buku, majalah, surat kabar, kamus, ensiklopedia, laboratorium, video, masyarakat, alam, dan sebagainya.

Sementara itu, dalam Petunjuk Teknis Kurikulum 1994 (1996: 26) dinyatakatan bahwa "metode tanya jawab adalah suatu cara mengajar atau menyajikan materi melalui pengajuan pertanyaan-pertanyaan yang mengarahkan anak memahami materi tersebut. Penggunaan metode ini dengan baik dan tepat, akan dapat merangsang minat dan motivasi anak dalam belajar. Beberapa hal yang perlu diperhatikan dalam penggunaan metode tanya jawab adalah: 1) materi menarik dan menantang serta memiliki nilai aplikasi tinggi, 2) pertanyaan bervariasi, meliputi pertanyaan tertutup (pertanyaan yang jawabannya hanya satu kemungkinan) dan pertanyaan terbuka (pertanyaan dengan banyak kemungkinan jawaban), 3) jawaban pertanyaan itu diperoleh dari penyempurnaan jawaban-jawaban anak, dan 4) dilakukan dengan teknik bertanya yang baik. (Depdikbud, 1996: 26).

Berdasarkan pembahasan diatas, maka dapat disimpulkan bahwa metode tanya jawab adalah suatu metode pembelajaran yang dilakukan dengan cara pengajuanpengajuan pertanyaan yang mengarahkan anak untuk memahami pelajaran dalam rangka mencapai tujuan pembelajaran.

\section{METODE PENELITIAN}

Metode penelitian yang digunakan dalam penelitian ini adalah metode tanya jawab, dalam pelaksanaan metode tanya jawab, pertanyaan yang di rumuskan dan yang di gunakan dengan tepat dapat menjadi alat komunikasi yang ampuh antara guru dan anak. Menurut Cliat,et.al(1992) dalam kostelnik (1999) dalam stategi pembelajaran TK (2014:7.12) ada beberapa langkah-langkah pelaksanaannya yaitu:

1. Ajukan hanya satu buah pertanyaan pada satu waktu. Rencanakan pertanyaan yang dibuat secara cermat.

2. Berikan waktu yang cukup bagi anak-anak untuk menjawab pertanyaan yang diajukan. Jangan perlihatkan sifat tidak sabar, atau kesal dan merusak pikiran anak dengan menjawab pertanyaan sendiri.

3. Ajukan pertanyaaan kepada seluruh anak, tidak hanya individual, ajaklah semua anak untuk berfikir tentang pertaan yang dilontarkan guru

4. Dengarkan secara cermat jawaban yang diberikan anak, hargai mereka dengan memberikan pujian.

5. Jika jawaban yang diberikan anak-anak ternyata salah atau kurang tepat, tindakan lanjut dengan mengatakan sesjuatu yang menyenangkan mereka. Misalnya "ayo jawabannya bisa lebih lengkap lagi?".

6. Jika ada jawaban dari anak yang salah maka hargai dan berikan anak jawaban yang benar kemudian jelaskan jawaban yang benar itu dengan jelas, agar tidk terjadi salah pahan antara guru dan anak.

Teknik analisis data bertujuan untuk menganalisis meningkatnya kemampuan berbahasa anak dengan penerapan metode tanya jawab pada anak Kelompok B RA Aisyiyah Bustanul Athfal Desa Sumber Makmur Kecamatan Tapung.

Berdasarkan hasil pengumpulan data melalui instrument observasi dilakukan teknik analisis data untuk menguji hipotesis tindakan adalah dengan menggunakan data kuantitatif. Diperoleh dari membandingkan ketuntasan belajar (prosentase yang 
memperoleh bintang tiga dan bintang empat) antara waktu sebelum dilakukan tindakan, tindakan siklus I dan tindakan siklus II. Menghitung persentase anak yang mendapatkan bintang $1(\star)$, bintang $2(\star \star)$, bintang $3(\star \star \star)$, dan bintang $4(\star \star \star \star)$ dengan menggunakan rumus sebagai berikut:

Keterangan:

$$
\mathrm{P}=\frac{\mathrm{f}}{\mathrm{N}} \times 100 \%
$$

$\mathrm{P}$ : Persentase anak yang mendapat bintang tertentu

$\mathrm{F}$ : Jumlah anak yang mendapat bintang tertentu

$\mathrm{N}$ : Jumlah anak keseluruhan

\section{HASIL DAN PEMBAHASAN}

Pelaksanaan penelitian siklus I dimulai pada tanggal 16 April 2018 sampai 18 April 2018. Siklus I dilakukan dalam 3 kali pertemuan dengan tema alat komunikasi. Berdasarkan kesepakatan guru dan peneliti, penelitian dilakukan sesuai dengan RPPH yang telah dibuat sehingga pembelajaran dapat berjalan efektif.

Pelaksanaan dilakukan oleh peneliti dan guru dengan melihat perbandingan antara data sebelum tindakan dan sesudah tindakan dilakukan pada siklus I pada grafik berikut.

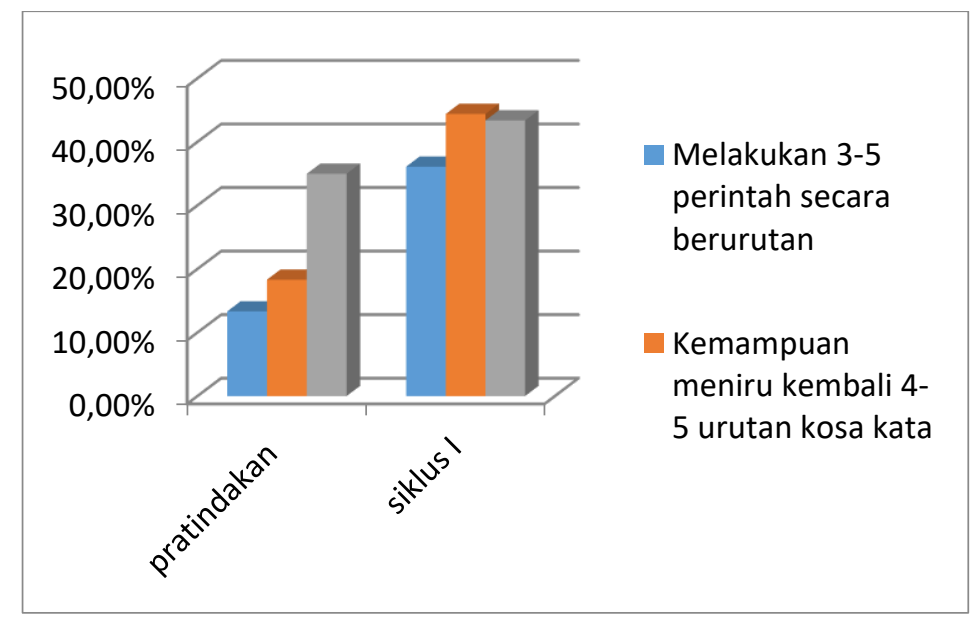

Gambar grafik rekapitulasi hasil pratindakan dan siklus I

Kemampuan berbahasa anak siklus I telah mengalami peningkatan, akan tetapi persentase tertinggi pada masing-masing indikator masih pada kriteria cukup. Persentase juga belum mencapai $76 \%$ sesuai dengan yang ditentukan peneliti. Hal ini terjadi karena ada beberapa kendala yang dihadapi dalam siklus I antara lain yaitu kurangnya keaktivan anak dalam bertanya dan menjawab pertanyaan, kurang menariknya pertanyaan yang guru berikan sehingga membuat anak tidak tertarik bertanya, anak meras takut bertanya, dan tidak adanya reward yang di berikan guru kepada anak yang berani bertanya serta menjawab.

Siklus II dilaksanakan selama 3 kali pertemuan dengan tema alat komunikasi. siklus II dimulai pada hari senin, 23 April 2018 dan berakhir pada tanggal 25 April 2018. Selama kegiatan siklus II guru memberikan banyak waktu kepada anak untuk bertanyatanya tentang kegiatan pembelajaran agar penerapan metode tanya jawab berjalan dengan lancar.

Setelah dilakukan Siklus II oleh peneliti dan guru kelas diakhir Siklus II. Dalam refleksi ini dibahas mengenai proses pembelajaran yang terjadi saat melakukan tindakan.

Aulad : Journal on Early Childhood, 2018 1(1), 1 - 7 
Anak sudah dapat melakukan perintah dengan benar, dapat menguasai kosa kata, dan berperak aktif dalam penerapan metode tanya jawab serta dapat menjawab pertanyaan dengan lengkap. Hal ini disebabkan karena adanya motivasi guru dan adanya reward.

Kemampuan berbahasa anak kelomlop B RA Aisyiyah Bustanul Athfal meningkat sebesar $34,52 \%$ yakni dari $43,48 \%$ pada siklus I menjadi $78 \%$ pada siklus II dan sudah memenuhi kriteria keberhasilan $>76 \%$ sehingga penelitian dirasa cukup dan diberhentikan sampai siklus II.

Penerapan metode tanya jawab di kelompok B RA Aisyiyah Bustanul Athfal Kabupaten Kampar terbukti mampu meningkatkan kemampuan berbahasa anak antar siklus dapat dilihat pada tabel berikut:

\begin{tabular}{|c|c|c|c|}
\hline & Pratindakan & Siklus I & Siklus II \\
\hline Persentase & $22,2 \%$ & $43,48 \%$ & $78 \%$ \\
\hline Kategori & Kurang baik & Cukup baik & Sangat baik \\
\hline
\end{tabular}

Berdasarkan Tabel 4.5 diatas terlihat jelas bahwa dari siklus I sampai Siklus II mengalami peningkatan kemampuan berbahasa. Ini menunjukan bahwa penerapan metode tanya jawab tepat digunakan untuk meningkatkan kemampuan berbahasa anak. Kemampuan anak juga meningkat dari pratindakan $22,2 \%$ menjadi $43,48 \%$ siklus I, dan semakin meningkat siklus II menjadi $78 \%$. persentase peningkatan antar siklus tergambar pada grafik berikut

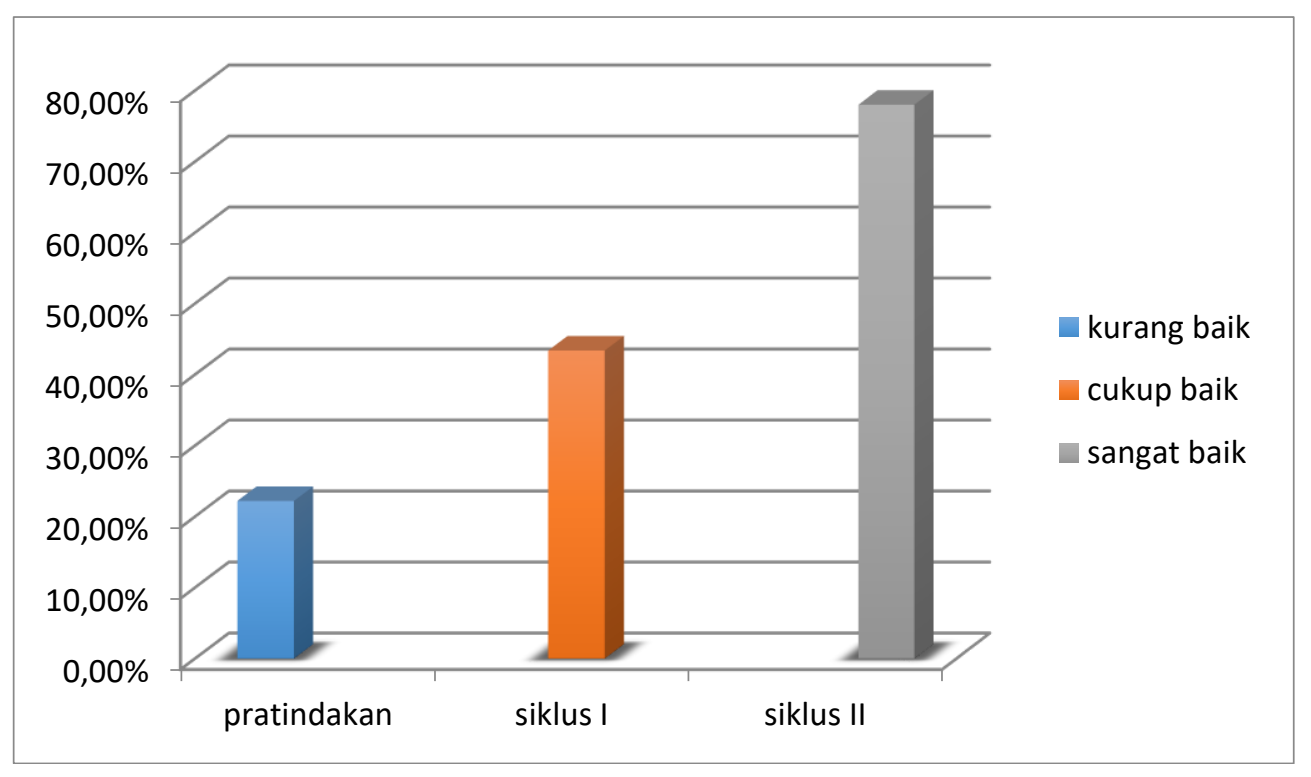

Berdasarkan grafik diatas, terlihat jelas bahwa terdapat peningkatan yang signifikan pada kemampuan berbahasa anak dari siklus I kesiklus II.

Perkembangan kemampuan berbahasa anak kelompok B RA Aisyiyah Bustanul Athfal Desa Sumber Makmur dengan penerapan metode tanya jawab umumnya anak berkembang sangat baik (BSB). Perkembangan kemampuan berbahasa anak kelompok B RA Aisyiyah Bustanul Athfal Desa Sumber Makmur pada pratindakan anak yang mendapat skor BSB $0 \%$ dan pada siklus I meningkat menjadi $40.1 \%$ lalu meningkat lagi pada siklus II menjadi $91.1 \%$ berkembang sangat baik karena adanya peningkatan anak dalam kategori berkembang sangat baik pada siklus II dibandingkan pada siklus I dan

Aulad : Journal on Early Childhood, 2018 1(1), 1 - 7 
berkurangnya anak dalam kategori belum berkembang (BB) dan Mulai Berkembang (MB) pada setiap kegiatan.

Dalam penerapan metode tanya jawab, guru harus memastikan anak untuk memberikan respon karena antara respon dengan kemampuan berbahasa memiliki hubungan yang sangat erat, hal ini dapat dilihat pada anak yang responnya aktif rata-rata kemampuan berbahasanya berada pada tingkat BSB. Guru harus memastikan menggunakan interaksi ektratekstual ketika menggunakan penerapan metode tanya jawab kepada anak, sehingga anak tertarik untuk mengemukakan pendapat dan menjawab pertanyaa yang diberi oleh gurunya agar suasana di kelas tidak membosankan.

Agar kemampuan berbahasa anak dengan penerapan metode tanya jawab dilakukan dengan kegiatan yang menyenangkan dan pemilihan media dalam kegiatan belajar anak yang menarik di setiap kegiatan, sebaiknya guru membuat perencanaan pembelajaran yang lebih baik dengan mempersiapkan rencana pelaksanaan pembelajaran harian (RPPH) serta menyediakan media/ alat dan bahan yang tepat dalam pembelajaran. Dunia anak adalah dunia bermain, oleh karena itu proses pembelajaran harus tetap dilaksanakan untuk membuat anak belajar dengan menyenangkan bukan terpaksa, yaitu belajar melalui permainan yang diberikan. Dengan meningkatnya kemampuan berbahasa anak dengan penerapan metode tanya jawab, maka guru juga dapat menerapkan kegiatan ini untuk meningkatkan kemampuan anak di bidang lain. Keterampilan dan strategi guru dalam pembelajaran sangat berpengaruh terhadap minat belajar anak, maka perbanyaklah ide-ide pembelajaran dan media pembelajaran sehingga anak tidak merasa bosan dengan kegiatan yang diterapkan. Sebaiknya guru lebih sering membiasakan anak untuk menstimulus kemampuan berbahasa anak sejak usia dini untuk menghindari keterlambatan anak dalam berbahasa khususnya berbicara, sehingga anak tidak mengalami kesulitan dalam menghadapi pendidikan.

\section{SIMPULAN}

Berdasarkan hasil penelitian dapat disimpulkan bahwa kemampuan berbahasa anak pada Kelompok B RA Aisyiyah Bustanul Athfal Desa Sumber Makmur dapat ditingkatkan dengan penerapan metode tanya jawab.

\section{UCAPAN TERIMAKASIH}

Dalam penulisan skripsi ini, tentunya tidak terlepas dari bantuan dan dukungan dari berbagai pihak. Oleh karena itu, dalam kesempatan ini peneliti menyampaikan ucapan terima kasih kepada dosen pembimbing, pihak RA Aisyiyah Bustanul Athfal Sumber Makmur yang telah bersedia menerima penulis untuk melakukan penelitian. Keluarga tercinta dan Teman-teman Prodi PG-PAUD yang telah begitu banyak memberikan do'a dan dukungan.

\section{DAFTAR PUSTAKA}

Abdul, Majid (2008). Perencanaan pembelajaran mengembangkan standar kompetensi guru. Tangerang Selatan UT.

Arikunto (2012). Penelitian tindakan kelas. Jakarta : Bumi Aksara.

Azhar,A (2006). Media Pembelajaran. Jakarta: PT Raja Grafindo Persada.

Badudu (2003). Metode pengembangan bahasa. Tangerang Selatan : UT

Bromle.(1992, 1-21).metode pengembangan bahasa. Tangerang Selatan:

Cliat.et.al .(1992, 7-12). Strategi pembelajaran TK.Tangerang Selatan : UT. 
Depdiknas, Kurikulum berbasis kompetensi TK, (Jakarta: Dorektorat Jendral Pendidikan Dasar Menengah, 2000)

Elin, Rusoni (2006). Pengembangan kemampuan. Tangerang Selatan : UT.

Halliday, Hetherington. (1979,254). Metode pengembangan bahasa.Tangerang selatan: UT.

Jumanis (2004). Karakteristik kemampuan bahasa anak. Tangerang Selatan : UT.

Kemendiknas. (2010). Kurikulum Taman Kanak-kanak. Kampar: GOPTKI.

Lenneberg (Martinis 2010). Perkembangan kemampuan bahasa. Tangerang Selatan : UT.

Majid, A.(2008, 140). Perencanaan pembelajaran mengembangkan standarkompetensi guru. bandung : rosda karya

Marleni, L. (2016). Improving Students' Listening Comprehension Of Narratives By Using Movies As Media At Grade XI IPA 5 Of SMAN 2 Bangkinang.Jurnal Obsesi : Journal Of Early Childhood Education, 1(1), 20-26. doi:10.31004/obsesi.v1i1.63

Marleni, L. (Improving Reading Comprehension By Using Jigsaw Strategy At Stkip Pahlawan Tuanku Tambusai : Journal Of Englis Languange And Education, [S.I], v. 2, n, 1, p. 13, feb. 2017, ISSN 2597-685.

Novivin. (2014,10).Tahap tahap perkembangan bahasa anak. [Online]. Tersedia dalam: http://blogspot.co.id/2014/10/tahap-tahap-perkembangan-bahasa-anak.html.

Rayandra, A (2011). Kreatif Mengembangkan Media Pembelajaran. Jakarta: Gaung Persada Press

Roestiyah,N.K.(1986,70).dikdatik metode.jakarta.

Rohimabdur. (2013,12). Metode tanya jawab. [Online]. Tersedia dalam : http://blogspot.co.id/2013/12/metode-tanya-jawab.html

Sadiman, Arief , dkk. (2011). Media Pendidikan. Jakarta: Rajawali Press.

Soetomo.(1993, 150).dasardasar interaksi belajar mengajar.surabaya.

Sukardi (2004). Penelitian tindakan kelas. Tangerang Selatan : UT.

Sudirman (2010). Metode pengembangan bahasa . Tangerang Selatan : UT

Sugiyono (2010). Metode penelitian. Tangerang Selatan : UT.

Sujiono, Nurani, Y. (2009). Konsep Dasar Pendidikan Anak Usia Dini. Jakarta: PT Indeks.

Stepen, Robbins (2003). Perilaku prganisasi. Tangerang Selatan : UT.

Syaiful,dkk.(1996, 140).dalam belajar mengajar. Jakarta.

Yusuf .(2014, 35).metode pengembangan prilaku dan kemampuan dasar aud. Tangeran Selatan : Universitas Terbuka. 